\title{
O QUE A TELENOVELA DIZ SOBRE A VELHICE? REPRESENTAÇÕES DA BELEZA E DO CUIDADO DE SI EM PASSIONE
}

\author{
Laura Hastenpflug Wottrich ${ }^{1}$
}

\begin{abstract}
RESUMO
$\mathrm{O}$ artigo analisa as representações sociais da velhice na telenovela a partir das categorias do cuidado de si e da beleza. Analisou-se a telenovela Passione através do modelo Codificação/Decodificação desenvolvido por Stuart Hall a partir da releitura de Ronsini (2010). Os resultados mostram a importância da telenovela na veiculação das representações. Em Passione, distintos sentidos entram em disputa, avançando na construção de uma identidade mais positiva para a velhice.
\end{abstract}

PALAVRAS-CHAVE: velhice, telenovela, representações sociais.

\section{RESÚMEN}

Este artículo analiza las representaciones sociales de la vejez en la telenovela a partir de la categoría cuidado por si mismo y belleza. La telenovela Passione fue analizada a través del modelo Codificación/Decodificación desarrollado por Stuart Hall a partir de la relectura de Ronsini (2010). Los resultados muestran la importancia de la telenovela en la exhibición de las representaciones. En Passione, distintos sentidos asoman a la disputa, avanzando en la construcción de una identidad más positiva para la vejez.

PALABRAS CLAVE: vejez, telenovela, representaciones sociales

\begin{abstract}
This paper analyzes the social representations of ancient age in telenovela from the category of beauty and personal care. We analyzed the telenovela Passione through the model Encoding/decoding developed by Stuart Hall from the reexamination of Ronsini (2010). The results show the importance of telenovela on the exposure of representations. In Passione, different senses come into dispute, forging a more positive identity for ancient age.
\end{abstract}

KEY WORDS: ancient age, telenovela, social representations.

\section{Introdução}

Este $\operatorname{artigo~}^{2}$ busca investigar as representações sociais da velhice na telenovela a partir de uma categoria específica, da beleza e cuidado de si. Buscamos investigá-la a partir da telenovela Passione ${ }^{3}$, veiculada no horário nobre da Rede Globo entre 2010 e 2011. No percurso da investigação, inicialmente trazemos considerações sobre o papel da mídia na elaboração e circulação das representações sociais na contemporaneidade. Após, aproximamo-nos do objeto de estudo - a telenovela, relacionando-o ao foco da pesquisa, a questão das representações do cuidado de si e da beleza na velhice. Em 
seguida, traçamos a proposta teórico-metodológica e apresentamos a análise. Por fim, discorremos sobre o que podemos concluir a partir de nossa análise.

\section{A centralidade das mídias e as representações}

A importância central que a mídia assume no contexto contemporâneo tem sido problematizada por várias vertentes teóricas nos estudos de comunicação. Com diferenciações epistemológicas, os autores buscam compreender as relações entre mídia e sociedade e suas implicações para a configuração do tecido social e constituição dos sujeitos.

Fausto Neto (2008) comenta que por muito tempo o campo de estudos dedicouse a compreender e reconhecer a centralidade dos meios na organização de processos internacionais entre os campos sociais. Nos últimos trinta anos, no entanto, "a convergência de fatores sócio-tecnológicos, disseminados na sociedade segundo lógicas de ofertas e de usos sociais produziu [...] profundas e complexas alterações na constituição societária, nas suas formas de vida, e suas interações" (FAUSTO NETO, 2008, p. 92). Ainda segundo o autor, tais transformações dizem respeito principalmente à disseminação de novos protocolos técnicos e à intensificação de processos que transformam tecnologias em meios de produção, circulação e recepção de discursos.

Trata-se de admitir a existência de uma cultura própria à esfera midiática, que influi profundamente na constituição das lógicas e práticas sociais. Ao mencionarmos a cultura da mídia, não dizemos respeito a um fenômeno auxiliar, uma tendência que se encontra aparte da sociedade. A cultura da mídia é a matéria-prima a partir da qual o tecido social se constitui - em suas lógicas, seus esquemas perceptivos e organização.

Douglas Kellner (2001) defende a expressão “cultura da mídia”, por entender que a mesma expressa a colonização da cultura pela esfera midiática, da suplantação pela mesma de outros modos de cultura, como o livro e a palavra falada. Afinal, as pessoas despendem, atualmente, grande parte do seu tempo "[...] ouvindo rádio, assistindo à televisão, freqüentando cinemas, convivendo com música, fazendo compras, lendo revistas e jornais, participando dessas e de outras formas de cultura veiculadas pelos meios de comunicação" (KELLNER, 2001, p.11). A mídia, ao valerse de determinados significados para a construção de representações, atribui sentidos específicos às práticas sociais, os quais incidem sobre a percepção que temos dos mesmos. Como sistema de representação social, assume uma posição privilegiada na 
construção de significados - e conseqüente classificação - das práticas sociais, forjando identidades.

Entendemos as representações sociais como um fenômeno de produção do conhecimento, através do qual os indivíduos e grupos sociais compreendem o mundo a sua volta e comunicam aquilo que já sabem (Moscovici, 2009). Mais do que algo relegado ao plano das ideias, as representações tornam-se um saber prático, senso comum que têm por principal função tornar o não familiar, familiar. As representações sociais dão às pessoas, acontecimentos ou objetos "[...]uma forma definitiva, as localizam em determinada categoria e gradualmente as colocam como um modelo de determinado tipo,distinto e partilhado por um grupo de pessoas" (Idem, p.34). Significa dizer, relacionando à temática do trabalho, que as representações sociais sobre a velhice têm a função de tornar familiar para aqueles que representam (idosos) algo que não lhes é familiar (o envelhecimento), constituindo suas práticas e saberes sobre o mundo.

Não são ideias e realidades criadas pelos indivíduos, pois vem de uma estrutura preexistente, numa sequencia de elaborações e classificações do mundo elaboradas ao longo do tempo. Contudo, as representações sociais têm sua efetividade justamente porque são cotidianamente ressignificadas e reelaboradas por indivíduos, grupos e instituições.

A mídia conforma sistemas de representação que arranjam determinados significados às práticas sociais, propõe posições de sujeito às quais podemos ou não nos filiar. Analisar as representações sociais veiculadas pela mídia permite apreender a circulação dessas representações e suas interações com a sociedade na conformação das identidades e produção da cultura. Pensando nos produtos da mídia, a telenovela se torna um lugar privilegiado para analisá-las.

\section{Telenovela e suas representações (da velhice)}

Em estudos realizados em 2008, pesquisadores do Banco Interamericano de Desenvolvimento (BID) mostram uma relação efetiva entre as representações realizadas pela telenovela brasileira e as transformações ocorridas no âmbito social. É o caso, por exemplo, das taxas de fertilidade feminina e da escolha do nome dos filhos:

A redução das taxas de fertilidade foi maior em anos imediatamente seguintes à exibição de novelas que incluíam casos de ascensão social, e para mulheres com idades mais próximas da idade da protagonista feminina da novela. As novelas também influenciaram a escolha dos nomes dos filhos. A probabilidade de que os 20 nomes mais populares em uma determinada área 
incluíssem um ou mais nomes de personagens de uma novela exibida naquele ano foi de $33 \%$ se a região recebesse o sinal da Globo. Em regiões sem acesso à Globo, a probabilidade foi de apenas 8,5\%. (BID, 2008, s/p).

A pesquisa embasa o que estudiosos da telenovela problematizam e os telespectadores vivenciam: a grande relevância que o gênero assume, no país, enquanto sistema de representação das práticas cotidianas, da cultura nacional e de valores morais. Atualmente, de sessenta a oitenta milhões de brasileiros assistem regularmente às novelas noturnas em português (BID, 2008). Criadas ulteriormente às radionovelas e teleteatros, as telenovelas brasileiras diárias exibidas em horário nobre foram introduzidas em 1963, apesar de sua veiculação - ainda que esparsa - ser datada de 1951. Eficiente na atração das audiências através de sua trama, o gênero consolidou-se na programação televisiva a partir de 1970 (HAMBURGER, 2005).

Em um ambiente permeado pela cultura midiática, a telenovela emerge como um gênero importante para apreender como a mídia apropria-se das representações sociais e as veicula para os receptores, os quais as ressignificam em seu processo de constituição identitária. Enquanto sistema de representação, o gênero apropria-se de determinados significados, classificando-os e dotando-os de sentidos através das tramas. O caráter cotidiano da veiculação da telenovela, a relação que cria com seus receptores, sua capacidade de acentuar a fisionomia da cultura brasileira (JACKS, 1999), o contínuo processo de reconfiguração da narrativa a partir das demandas esboçadas pelas audiências: vários são os fatores que contribuem para que a análise do gênero seja exemplar como forma de compreender as relações entre os meios de comunicação e a sociedade.

Tais relações têm sido estudadas principalmente a partir da década de 70, quando surgiram diversos trabalhos preocupados em compreender a peculiaridade e relevância do gênero no contexto brasileiro. Na década de 90, foram produzidas 26 pesquisas, sendo que 16 fizeram menção a distintos aspectos da telenovela e 10 a sua recepção (JACKS, MENEZES; PIEDRAS, 2008).

No que tange ao recorte de nossa pesquisa, ou seja, a relação entre velhice e telenovela, o levantamento realizado revela a escasse $z^{4}$ de estudos dedicados a compreender as intersecções entre o gênero, representações e velhice. Isso se torna compreensível a partir do entendimento da recente atenção que a velhice adquiriu como foco de pesquisa, principalmente no Brasil. A expansão da população idosa no país, dada pela elevação da expectativa de vida do brasileiro e reduzidas taxas de 
mortalidade, aos poucos transforma os modos como a velhice é vista, teorizada e representada na sociedade, assim como os modos como o próprio indivíduo idoso concebe sua trajetória e perspectivas de vida.

Priorizamos esta perspectiva de pesquisa por três motivos principais: 1) em experiências anteriores de pesquisa com o público idoso, pudemos averiguar o quanto esses receptores são telespectadores ativos da telenovela. Essa idéia é confirmada em pesquisas realizadas pela Fundação Perseu Abramo (NERI, 2007), nas quais assistir televisão figura como primeira opção de lazer entre os idosos brasileiros, com $93 \%$ da preferência; 2) a particular importância que a mídia assume enquanto propagadora de representações sobre a velhice (DEBERT, 1999), em um contexto no qual esse período da vida é cotidianamente ressignificado, principalmente face à expressividade demográfica da população idosa e sua emergência enquanto público consumidor; 3) o anseio de compreender que arranjos a telenovela realiza na representação dos idosos, com foco na dimensão do cuidado de si e beleza. Frente a um contexto em que a mídia é tida como responsável pela valorização exacerbada da juventude e negação do envelhecimento através de suas matérias e anúncios publicitários, como a telenovela se posiciona? De que forma representa a beleza e o cuidado de si na velhice? Com foco nessas indagações, empreendemos a análise de Passione.

\section{Como analisar a novela? Percurso teórico-metodológico}

O percurso de análise das representações da beleza e cuidado de si na novela foi guiado pelo modelo "Codificação/Decodificação", apresentado à comunidade acadêmica em 1970 por Stuart Hall. A proposta do autor traz pistas valiosas sobre a compreensão do processo comunicativo a partir de programas televisivos. Baseamo-nos especialmente na releitura do modelo realizada por Ronsini (2010).

Hall diz que toda cultura ou sociedade tem a tendência de "[...] impor suas classificações do mundo social, cultural e político. Essas classificações constituem uma ordem cultural dominante, apesar de esta não ser nem unívoca nem incontestável" (Hall, 2003, p.374). A essa ordem cultural dominante, o autor denominou de "sentidos dominantes" ou "preferenciais".

Codificar significa exercer o poder na tentativa de hegemonizar a audiência (idem). Essa tentativa nunca é bem-sucedida, pois o texto se abre a uma variedade de significados que não foram previstos no momento da produção da mensagem. A telenovela é um produto cultural massivo, perpassado pelas lógicas de produção da 
Rede Globo que são intimamente relacionadas aos significados dominantes dentro da sociedade. A avidez pela lealdade das audiências leva a trama a circular essas representações.

Contudo, há também brechas para a construção de outros sentidos que muitas vezes negociam e raramente se opõem aos dominantes. A esses, Hall denominou de sentidos negociados e opositivos, respectivamente. Os sentidos opositivos opõem-se à lógica dominante apresentam a mensagem dentro de algum referencial alternativo. Já os sentidos negociados são caracterizados por oscilar entre o sentido dominante e o opositivo.

As representações da mídia existem na medida em que são embasadas na cultura e presentes na sociedade. Para entendê-las, antes de imergir na ficção, foi imprescindível compreender a realidade. Para isso, inicialmente realizamos uma aprofundamento na literatura a fim de investigar a construção histórica da velhice e as representações sociais que existem sobre esse período da vida. Em concomitância, no trabalho de campo observamos o cotidiano das idosas entrevistadas, como elas entendiam e viviam a velhice. A partir disso, foi possível delinear os sentidos dominantes e opositivos de representação da beleza e cuidado de si, o que nos embasou para analisar as representações de Passione.

\section{As representações da beleza e cuidado de si}

Ao pensarmos nas categorias, a dimensão do cuidado de si e beleza foi a que inicialmente ganhou mais relevo, pois tanto os autores quanto as entrevistadas sinalizavam ser uma perspectiva fundamental na caracterização e vivência da velhice. Na literatura, Mercadante (2005) comenta que o corpo se torna a primeira via de identificação e reconhecimento da velhice, pelo qual o estigma se reforça e novas possibilidades de significação são criadas. Para as entrevistadas, em etapa posterior da pesquisa, o corpo também mostrava-se central na classificação da velhice. Ser velho, para além da questão etária, estava no modo de se vestir, nas rugas aparentes, no viço e motivação para as tarefas cotidianas e na manutenção da saúde.

Nas representações dominantes, o cuidado de si torna-se um veículo da reprivatização da velhice (DEBERT, 1999), pois é através do manejo da aparência e do cuidado da saúde que a responsabilização do indivíduo por seu processo de envelhecimento se concretiza. Cabe a ele cuidar de si para postergar - ou, abusando da radicalidade, evitar o envelhecimento. 
Devido ao amplo processo de transformações que atravessa esta etapa da vida, torna-se difícil definir o que seria uma representação opositiva da beleza e cuidado de si a partir da especificidade desta categoria. Entendemos que é quando a velhice é mostrada como uma construção dependente de vários fatores (cuidados individuais, políticas públicas, genética, trajetória de vida, etc) e não somente do cuidado consigo; e o corpo idoso é aceito em sua materialidade, sem que o indivíduo seja desqualificado por isso. Uma possível estética para a velhice se delineia. As oposições jovem/saúde $\mathrm{X}$ velho/doente são desestabilizadas: a idosa não precisa atender aos ditames de um corpo jovem, mas também não necessariamente precisa enquadrar-se nas restrições normativas em relação à aparência estabelecidas socialmente para sua idade.

Para analisar essas perspectivas - os sentidos - em Passione, fizemos a leitura diária das sinopses dos capítulos e também nos baseamos na descrição dos personagens apresentada pelo site, que consideramos de relevância especial para compreender como os autores definem e desejam que o público os veja. A busca de matérias e referências da imprensa especializada sobre os desdobramentos da trama também foi uma estratégia utilizada.

$\mathrm{Na}$ análise, nos detivemos especialmente nas personagens femininas consideradas idosas. Isso porque acreditamos que a dinâmica de valorização do corpo e da beleza recai de forma muito mais intensa sobre as mulheres do que sobre os homens. A partir de consulta ao elenco, encontramos 11 personagens idosos, seis homens e cinco mulheres. São eles Brígida (Cleide Yácones), Antero Gouveia (Leonardo Villar), Bete Gouveia (Fernanda Montenegro), Eugenio Gouveia (Mauro Mendonça), Olavo da Silva (Francisco Cuoco), Clô Souza e Silva (Irene Ravasche), Nonno Benedetto (Emiliano Queiroz), Gemma (Aracy Balabanian), Valentina (Daisy Ludici), Fortunato (Flávio Micliaccio) e Diógenes Santarém (Elias Gleiser). Detivemos-nos na análise de Brígida, Valentina, Gemma, Bete Clô Souza e Silva e Candê (Vera Holtz). Essa última, por mais que não seja considerada uma personagem idosa - mas em fase de envelhecimento, foi incluída por fornecer reflexões importantes à análise.

\section{Beleza e cuidado de si em Passione}

A aparência corporal tentativa de retardamento dos sinais de idade, valorização/desvalorização individual a partir dos atributos físicos, associação de velhice à doença e os cuidados tomados com a saúde compuseram nossa perspectiva de análise desta dimensão. Apesar de tanto a literatura quanto as entrevistas afirmarem sua 
importância na configuração da velhice, tornou-se difícil entendê-la através das personagens, especialmente em relação à beleza. Essa dimensão levou-nos a pensar nas lógicas de produção do folhetim. As personagens, por mais que tenham uma construção dramática própria, carregam em si as características físicas e de aparência das atrizes que as interpretam. Pensar em sua aparência é relevar que, para estarem na trama, as atrizes já obedecem a um padrão estético de cuidado de si, postura corporal e figurino caro ao "padrão Globo de qualidade". A análise precisa necessariamente levar isso em conta.

Giddens (2002) comenta que o manejo do corpo não é produto do contexto moderno, mas sim algo que perpassa todas as culturas. $\mathrm{O}$ controle rotineiro do corpo integra os modos como nos movemos em sociedade. Para além de uma entidade física por nós "possuída", o corpo é um modo de práxis, a um sistema de ação importante para que mantenhamos um sentido coerente em relação a nós mesmos, à nossa autoidentidade. De outro modo, esse mesmo corpo - esse mesmo eu - é exibido para os outros em termos de sua corporificação. Assim, o corpo que manejamos torna-se importante no tracejo de uma biografia da auto-identidade ${ }^{5}$.

Para Giddens, isso não significa necessariamente dizer que estamos envoltos em uma sociedade narcisista na qual o culto a aparência depreda as formas de sociabilidade e as maneiras sadias de conceber-se no mundo. Para ele, seria miopia observar o fenômeno somente em relação aos novos ideais de aparência corporal ou como produção da lógica da propaganda. A construção reflexiva do eu estendida ao manejo do corpo é a dinâmica através do qual os indivíduos podem tecer coerência a sua autoidentidade, é aspecto constitutivo de uma ordem pós-tradicional. Assim, "Como outros aspectos da reflexividade da auto-identidade, o planejamento do corpo é mais frequentemente um envolvimento com o mundo exterior do que uma retirada defensiva dele" (GIDDENS, 2002, p.165).

Compartilhamos da visão do autor pelo esforço de não atribuir a priori um sentido negativo ao cuidado dedicado ao corpo, tanto nas representações da velhice veiculadas pela telenovela quanto nas vivências partilhadas pelas receptoras. O que está em jogo, acreditamos, não é tanto o montante de cuidados dedicados ao corpo, mas na significação que esses cuidados assumem. Essa é a perspectiva adotada por Costa (2004), quando pondera que o manejo do corpo pode descambar para um culto narcísico exacerbado, causador em grande parte dos transtornos de imagem corporal que observamos na atualidade como a vigorexia (abuso das atividades físicas), bulimia, 
anorexia e as compulsões por cirurgias estéticas; mas também ser um instrumento de realização dos indivíduos.

Em Passione, tentamos observar se há desqualificação dos personagens a partir de seus predicados corporais quando associados à velhice. Representações dominantes se delineiam quando o corpo é utilizado para reprivatizar a velhice, delegando ao indivíduo toda a responsabilidade por envelhecer. $\mathrm{O}$ corpo aqui é meio para negar a velhice (através de um processo de rejuvenescimento) ou para rechaçá-la (através das marcas aparentes do envelhecimento).

Não vimos nas representações da telenovela o corpo como meio de negação da velhice. Também não há o estabelecimento explícito de contigüidades entre cuidado com a aparência - vivência positiva da velhice ou descuido - vivência negativa. Somente em Valentina parece que há certo esforço em manter uma relação entre seu caráter e apresentação pessoal. Para caracterização da personagem, a atriz Daisy Lúdici teve que engordar cinco quilos e usa em cena a maquiagem borrada e roupas justas. Em uma entrevista $^{6}$, a atriz comenta que Silvio de Abreu pediu que ela nunca usasse mangas em cena e mantivesse uma "aura bagaceira", fosse desleixada. Nas cenas em que Clara e Valentina discutem, são comuns menções da neta ao "aspecto sujo" e ao "mau cheiro" da avó. Por associar a vivência negativa da velhice a um certo desleixo corporal, consideramos as representações de Valentina dominantes nesse aspecto. É também nossa perspectiva em relação a $C l \hat{o}$, apesar de diferir totalmente das representações da avó de Clara e Kelly.

Clô é a única que nega explicitamente a sua idade e, coincidentemente, é em quem o cuidado com aparência é mais evidente entre as personagens analisadas. Ela é muito vaidosa e são constantes as cenas em que vai ao shopping comprar roupas ou ao salão de beleza para se arrumar ${ }^{7}$. Consideramos essa personagem dominante pela negação que faz do processo de envelhecimento.

Há uma associação clara entre cuidado com a aparência e posição de classe. Isso é bem evidente na caracterização de Clô. Mulher de classe popular que ascendeu através do casamento, busca com sua forma de vestir e de se portar também elevar-se socialmente. Ela é a única personagem que nega a velhice na trama.

Bete e Brígida estão sempre impecavelmente vestidas e maquiadas, apesar do cuidado de si não perpassar as cenas. Idosas da classe alta tradicional, parecem ser naturalmente bem arrumadas e cuidadas. Já Clô esforça-se para construir uma aparência bela e jovial. Em Gemma,Candê, Bete e Brígida não identificamos representações 
dominantes aos moldes das que relatamos acima. Contudo, em suas vivências - a exceção de Brígida com relação à saúde - o cuidado com o corpo também não é problematizado explicitamente.

Essas personagens parecem negociadas, pois ao mesmo tempo em que não evidenciam que, para se ter uma boa aparência, além de vontade é necessário ter acesso a saúde, bons recursos financeiros e uma situação de vida estável, também não negam o envelhecimento. Talvez elas sinalizem a criação de uma possível estética para a velhice na telenovela, em que cabelos brancos e rugas não são sinal de desleixo pessoal e, ao mesmo tempo, não há um cuidado abusivo para com a aparência e uma busca desenfreada pela juventude.

\section{Considerações finais}

Torna-se difícil encontrar alguma personagem opositiva com foco na dimensão da beleza e cuidado de si em Passione, até mesmo pela própria lógica de produção do folhetim. Opor-se à lógica dominante seria problematizar a estética da velhice e as associações entre jovem=belo/ velho=gasto, feio; atitude que nenhuma das personagens assume. O discurso na novela sobre essa dimensão tende ora a associar a velhice ao desleixo corporal, reforçando uma representação estigmatizada (Valentina), ora mostrar a velhice como algo que deve ser evitado (Clô). Contudo, através das outras personagens (Bete, Gemma, Brígida e Candê) há espaço para negociação. Especialmente as três primeiras, que consideramos idosas. São mulheres que não tem uma estética desleixada, mas ao mesmo tempo não negam a velhice. Menções de Bete, Gemma e Brígida a essa etapa da vida, por mais que não sejam corriqueiras, acontecem.

As codificações da telenovela sobre a velhice diferem bastante do encontrado em outras esferas de produção da mídia, como a publicidade. Nessa, o envelhecer é também mostrado de uma forma positivada, contudo associado na maioria das vezes às características da juventude. Essa fase da vida transforma-se em um conceito publicitário estrategicamente posicionado para promover marcas e instituições (PEREIRA, 2010).

À juventude, são associados valores positivos como modernidade, felicidade, liberdade e novas realizações, os quais são posicionados em relação aos produtos e estimulados à adoção através de hábitos de consumo. Se por um viés, essas representações colocam a velhice em pauta e ampliam as possibilidades de vivências e a gama de serviços e produtos disponíveis, por outro exibem representações do 
envelhecimento como um processo que precisa ser necessariamente combatido. Essas representações partem muito mais de uma negação do processo de envelhecer do que a admissão do mesmo como algo natural da existência humana. A projeção dos valores e atributos dos jovens na materialidade de um corpo que envelhece faz com que as consequiências e perdas naturais desse período da vida sejam vistas com desconfiança, como sinal de lassitude moral e desleixo pessoal que precisam ser remediados através de cuidados específicos e individuais, realizados a partir do consumo (DEBERT, 2004, 2008).

Pelo que problematizamos na análise da telenovela, vemos que suas codificações tomam outro curso. A trama positiviza o envelhecer, mas sem adotar a juventude como um parâmetro régio de comportamentos e atitudes. A velhice é tomada em sua singularidade e desenvolvida a partir de parâmetros próprios, num processo contínuo de ancoragem (MOSCOVICI, 2009) com as representações sociais já estabelecidas, onde o já conhecido sobre a velhice é utilizado como base para a formulação de novos significados sobre ela.

Assim, não se torna possível pensar na telenovela - na veiculação das representações sociais da velhice a partir da categoria beleza e cuidado de si - como um processo determinista de reprodução da ideologia dominante, por mais submissa que sua produção seja às lógicas de mercado. Passione se torna um espaço de disputa de representações que são constantemente negociadas com a audiência. A trama, inserida em lógicas de poder socialmente estruturadas, dá espaço para a edificação de representações sociais distintas sobre a beleza e cuidado de si na velhice, avançando na construção de uma identidade mais positiva os idosos.

\section{Referências}

BANCO INTERAMERICANO DO DESENVOLVIMENTO. Novelas brasileiras têm impacto sobre os comportamentos sociais. Jan. 2009. Disponível em: < http://www.iadb.org/news/detail.cfm?id=5104\&lang=pt>. Acesso em 10 jul 2009.

COSTA, Jurandir Freire. O vestígio e a aura: corpo e consumismo na moral do espetáculo. São Paulo: Garamond, 2004.

DEBERT, Guita Grin. A reinvenção da velhice. São Paulo: Edusp, 1999.

Cultura adulta e juventude como valor., 04/2004, Revista Farmacêutica

Kairos, Vol. 7, pp.21-44, São Paulo, SP, BRASIL, 2004. 
.Velhice e Tecnologias do Rejuvenescimento, (Mesa-Redonda), 10/2008. 32 Encontro Anual da ANPOCS, Caxambu, MG, BRASIL.

FAUSTO NETO, Antônio. Fragmentos de uma "analítica" da midiatização. Revista MATRIZes, n.1, p. 89-105, Jan-jun. 2008

GIDDENS, Anthony. Modernidade e Identidade. São Paulo: Zahar, 2002.

HALL, Stuart . A centralidade da cultura: notas sobre as revoluções culturais do nosso tempo. In: Educação \& Realidade - Cultura, mídia e educação. Porto Alegre, v. 22, n.2, jul./dez, p.15-45, 1997.

Codificação/decodificação. In SOVIK, Liv, Da diáspora. Identidades e mediações culturais, Belo Horizonte, UFMG; Brasília, Humanitas, 2003.

HAMBURGER, Esther. O Brasil Antenado. A sociedade da novela. Rio de Janeiro: Jorge Zahar, 2005.

JACKS, Nilda (coord); MENEZES, Daiane; PIEDRAS, Elisa. Meios e audiências: a emergência dos estudos de recepção no Brasil. Porto Alegre: Sulina, 2008.

JACKS, Nilda. Querência: Cultura regional como mediação simbólica. Porto Alegre: Ed. Universidade/UFRGS, 1999.

KELLNER, Douglas. A Cultura da Mídia. São Paulo: EDUSC, 2001.

MERCADANTE, Elisabeth Frohlich. Velhice: uma questão complexa. In: CÔRTE, MERCADANTE, ARCURI (Orgs). Velhice, envelhecimento, complex(idade). São Paulo: Vetor, 2005.

MOSCOVICI, Serge. Representações sociais: Investigações em psicologia social. Petrópolis: Vozes, 2009.

NERI, Anita Liberalesso (0rg.). Idosos no Brasil: vivências, desafios e expectativas na terceira idade. São Paulo: Ed. Fundação Perseu Abramo, 2007.

PEREIRA, Claudia da Silva. Juventude como conceito estratégico para a publicidade. Comunicação, mídia e consumo. São Paulo: ESPM, v. 7, n. 18, p. 37-54, mar 2010.

RONSINI, Veneza V. M. A perspectiva das mediações de Jesús Martín-Barbero (ou como sujar as mãos na cozinha da pesquisa empírica de recepção). Trabalho apresentado no GT "Recepção, Usos e Consumos Midiáticos" do XIX Encontro da Compós, na PUC- RJ, no Rio de Janeiro, em junho de 2010.

SILVA, Lourdes Pereira. Identidade e telenovela como objetos de análises: contexto da produção científica discente. Trabalho apresentado ao Núcleo de Pesquisa "Ficção Televisiva", do XXXIII Encontro Brasileiro de Ciências da Comunicação, em Caxias do Sul/RS em setembro de 2010.

Notas 
${ }^{1}$ Publicitária, Mestre em Comunicação (POSCOM/UFSM), professora substituta do Departamento de Ciências da Comunicação na Universidade Federal de Santa Maria (UFSM). email: lwottrich@gmail.com.

${ }^{2} \mathrm{O}$ texto aqui apresentado é um recorte da dissertação de mestrado "Envelhecer com Passione: a telenovela na vida de idosas das classes populares", defendida em março de 2011 sob orientação da prof. Dra. Veneza Mayora Ronsini.

${ }^{3}$ Veiculada no horário nobre da Rede Globo de maio de 2010 a janeiro de 2011, a trama é de autoria de Silvio de Abreu com colaboração de Vinicius Vianna, Sergio Marques e Daniel Ortiz e direção de Carlos Araújo, Luiz Henrique Rios, Natalia Grimberg, Allan Fiterman e André Câmara.

${ }^{4}$ Em levantamento realizado, constatamos a existência de apenas um estudo, uma tese, que se dedica a compreender as relações entre velhice e telenovela. Para mais informações, ver OLIVEIRA, Maria Helena Castro de. Estrelas refletidas nas noites globais : estudo de representações de idosos nas telenovelas da rede Globo de televisão. Tese (Programa de Pós-graduação em Comunicação Social da Pontifícia Universidade Católica do Rio Grande do Sul) - PUCRS. Porto Alegre, 2008.

5 Para Giddens, "A auto-identidade, em outras palavras, não é algo simplesmente apresentado, como resultado das continuidades do sistema de ação do indivíduo, mas algo que deve ser criado e sustentado rotineiramente nas atividades reflexivas do indivíduo (...) A auto-identidade não é um traço distintivo, ou mesmo uma pluralidade de traços, possuídos pelo indivíduo. É o eu compreendido reflexivamente pela pessoa em termos de sua biografia" (2002, p.54)

6 Passione: Vera Holtz e Dayse Ludici se destacam na trama. Disponível em http://extra.globo.com/lazer/canalextra/posts/2010/06/26/passione-vera-holtz-dayse-lucidi-se-destacamna-trama-303257.asp Acesso em 27 jun 2010.

${ }^{7}$ Sobre a caracterização da personagem, Irene Ravasche comenta: "Ela coloca tanto penduricalho! Nunca fiz uma personagem que tivesse tanta mala de adereços. Mas a Gogóia [figurinista de Passione] falou: a Clô não é uma árvore de Natal, ela tem informação. É como se ela lesse três revistas de moda e usasse tudo ao mesmo tempo". TELENOVELA PASSIONE. "A vida sexual deles é cheia de fantasia”, diz Irene Ravasche sobre Clô e Olavo. Disponível em : http://passione.globo.com/Bastidores/noticia/2010/06/vidasexual-deles-e-cheia-de-fantasia-diz-irene-ravache-sobre-clo-e-olavo>.html Acesso em 20 jun 2010. 